\title{
Úlcera de córnea por Pseudomonas stutzeri Pseudomonas stutzeri corneal ulcer
}

Fellipe Berno Mattos $^{1}$,Fernanda Spinassé Agostini² ${ }^{2}$, Marcelo Berno Mattos ${ }^{2}$, Diusete Maria Pavan Batista ${ }^{3}$

\section{ReSUMO}

Este relato aborda um caso atípico de úlcera de córnea em uma criança de 09 anos, causado pela bactéria Pseudomonas stutzeri, um micro-organismo oportunista cujo isolamento em olhos é extremamente raro.

Descritores: Pseudomonas stutzeri, doenças da córnea, úlcera da córnea, terapêutica

\begin{abstract}
This report discusses an unusual case of corneal ulcer in a child of 09 years old, caused by the bacteria Pseudomonas stutzeri, an opportunistic organism whose isolation in the eyes is extremely rare.
\end{abstract}

Keywords: Pseudomonas stutzeri, corneal disease, corneal ulcer, therapeutics

\footnotetext{
${ }^{1}$ Universidade Federal do Espírito Santo (UFES) - Vitória (ES) - Brasil;

${ }^{2}$ Universidade Federal do Espírito Santo (UFES) - Vitória (ES) - Brasil;

${ }^{3}$ Universidade Federal do Espírito Santo (UFES) - Vitória (ES) - Brasil.

Trabalho realizado no Departamento de Oftalmologia da Universidade Federal do Espírito Santo (UFES) - Vitória (ES) - Brasil

Os autores declaram inexistir conflitos de interesse

Recebido para publicação em 5/11/2011 - Aceito para publicação em 29/8/2011
} 


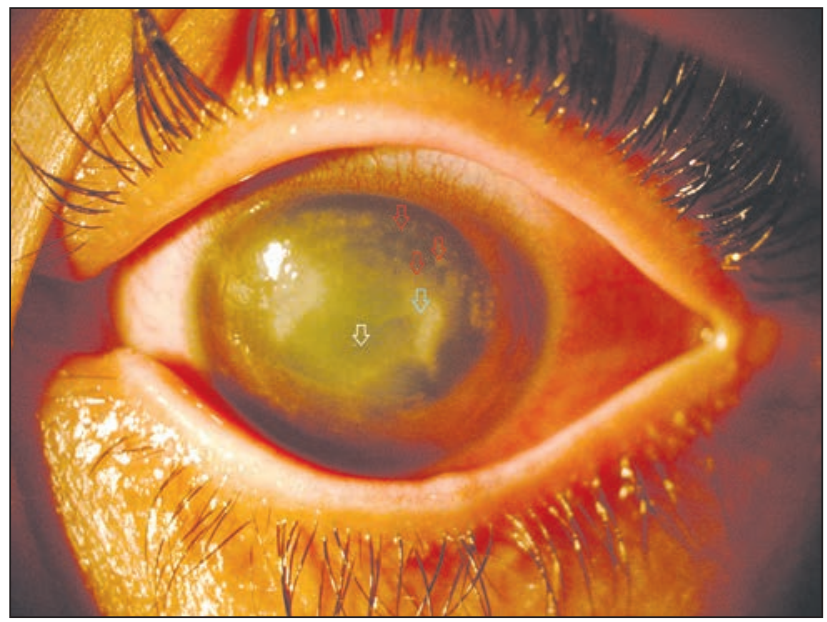

Figura 1: Iluminação difusa à biomicroscopia no segundo dia de atendimento em que é possível visualizar uma úlcera central rasa (seta branca) com infiltrado estromal anterior perilesional (seta verde), cercada perifericamente por triplo infiltrado em anel tipo imunológico (setas vermelhas), intensa hiperemia conjuntival e midríase farmacológica (após evidência de reação de câmara anterior ao exame)

\section{INTRODUÇÃO}

$\boldsymbol{P}$ eudomonas stutzeri é um bastonete Gram-negativo móvel por possuir um único flagelo polar. É um organismo ubíquo na natureza, encontrado difusamente em ambientes hospitalares ${ }^{(1)}$, estando geralmente associado à infecção oportunista, embora o acometimento ocular seja raro ${ }^{(2)}$.

Em 1973, o primeiro caso bem documentado de infecção por este agente foi descrito na literatura, relacionado com uma fratura de tíbia ${ }^{(3)}$. Desde então, alguns casos foram relatados, com grande espectro de acometimento (septicemia, osteomielite e artrite, endocardite, meningite, pneumonia e/ou empiema, ectima gangrenosa, ventriculite, infecção de aparelho urinário e ocular) ${ }^{(1-8)}$.

Neste estudo, reportamos os aspectos clínicos deste raro caso de ceratite por P. stutzeri, cuja descrição é a primeira na literatura nacional. A sensibilidade deste agente aos antibióticos, as similaridades clínicas com outras ceratites causadas por patógenos mais incidentes na população e a importância do exame laboratorial no diagnóstico e tratamento das ceratites são também discutidos.

\section{Relato do caso}

Paciente do sexo masculino, 09 anos, natural e procedente de Domingos Martins-ES, previamente hígido, atendido no Serviço de Oftalmologia do HUCAM/UFES devido ao quadro iniciado 20 dias antes da primeira con-

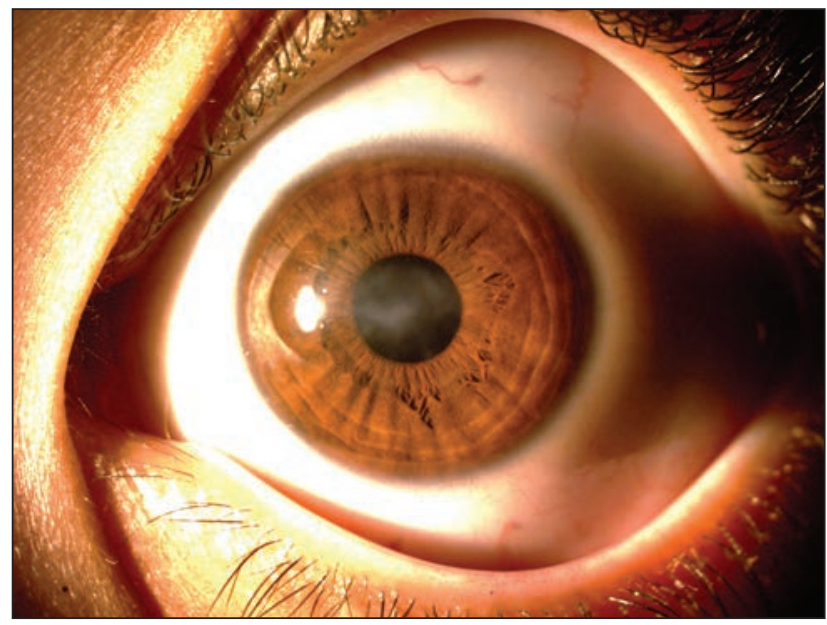

Figura 2: Iluminação difusa à biomicroscopia ao final do tratamento, evidenciando-se leucoma central residual

sulta de hiperemia conjuntival e redução de acuidade visual (AV) em olho esquerdo (OE), evoluindo com piora progressiva. Os sintomas surgiram após contato de pó de giz com a superfície ocular. Mãe relata que desde o princípio vinha lavando o olho diariamente com soro fisiológico, mantido aberto em geladeira há meses. Em nenhum momento a criança relatou dor, apenas leve desconforto ocular.

A AV não corrigida era de 20/25 no olho direito (OD) e 20/400 no OE. O OD era normal à biomicroscopia. Já o OE apresentava pequena úlcera central rasa medindo aproximadamente $2.2 \times 1.2 \mathrm{~mm}$, com infiltrado estromal anterior perilesional, cercada perifericamente por triplo infiltrado em anel tipo imunológico, hiperemia conjuntival leve, sem reação de câmara anterior. À palpação bidigital a pressão dos olhos parecia normal.

Com base na história da doença atual e nos achados clínicos evidenciados, foram aventadas as seguintes possibilidades etiológicas para o caso: fungo, herpes simples e Acanthamoeba. Para o auxílio diagnóstico realizou-se a coleta de material através do raspado de córnea, com a amostra sendo enviada para o Laboratório de Microbiologia do próprio hospital. O material colhido do paciente foi semeado nos seguintes meios de cultivo: ágar sangue, ágar chocolate e ágar Sabouraud, sendo também imersa em tioglicolato. Bacterioscopia corada pelo método de Gram realizada de imediato teve resultado negativo. Foi solicitado também o antibiograma. Foram então prescritos colírios 
fortificados de cefalotina $(50 \mathrm{mg} / \mathrm{ml})$ e amicacina $(25$ $\mathrm{mg} / \mathrm{ml}$ ) para serem usados de $1 / 1 \mathrm{~h}$.

O paciente evolui no dia seguinte com edema palpebral importante, hiperemia conjuntival intensa, mantendo úlcera com mesmas dimensões anteriores, mas apresentando pequeno hipópio $(1 \mathrm{~mm})$ e células $+/ 4+$ na câmara anterior (Figura 1). Mãe relata não ter tido condições financeiras de adquirir os colírios prescritos. Diante da incerteza quanto à etiologia bacteriana diante do quadro, o tratamento foi iniciado com moxifloxacino $0,5 \%$ apenas $4 / 4 \mathrm{hs}$, atropina $1 \% 8 / 8 \mathrm{hs}$ e carboximetilcelulose sódica $0,5 \% 4 / 4$ hs até o resultado da cultura. Com 48 horas de antibioticoterapia, mesmo em dose profilática, houve o desaparecimento do hipópio e não era mais possível visualizar reação inflamatória em câmara anterior, além de importante redução da hiperemia conjuntival.

$\mathrm{Na}$ cultura houve o crescimento da bactéria Pseudomonas stutzeri, cujo antibiograma demonstrava larga sensibilidade ao moxifloxacino e a inúmeros outros antibióticos, sendo ele mantido devido à boa resposta e aceitação da criança, na mesma posologia, até o final do tratamento.

Com um mês de terapia houve completo fechamento do defeito epitelial, enquanto que o anel imunológico apresentou redução gradual ao longo de 3 meses, restando por fim apenas o leucoma central cicatricial (Figura 2). A AV final do paciente, após este período, foi de 20/30.

\section{Discussão}

A ocorrência de lesão ocular associada à Pseudomonas stutzeri é extremamente rara, havendo relatos de casos de conjuntivite ${ }^{(1)}$, panoftalmite associada a abscesso orbitário ${ }^{(2)}$, endoftalmite após realização de cirurgia de catarata ${ }^{(5)}$ e apenas um caso de úlcera de córnea ${ }^{(6)}$.

Fatores de risco como trauma, infecção cutânea por outro micro-organismo, cirurgia prévia (provável aquisição nosocomial) e imunossupressão estão associados à maioria dos casos de infecção sistêmica e extraoculares descritas na literatura. No caso da úlcera de córnea anteriormente descrita por Brinser ${ }^{(6)}$, o paciente era portador de uma cicatriz corneana, possivelmente decorrente de infecção herpética prévia, podendo ter sido este o fator predisponente para o desenvolvimento da infecção pela $P$. stutzeri.

No presente relato, a infecção oportunista pode ter ocorrido em decorrência da associação da abrasão corneana pelo pó de giz, agravada pelo ato de coçar os olhos pela criança, mais a irrigação ocular com soro fisiológico, possivelmente contaminado. Por não haver mais amostra do soro, não foi possível realizar a avaliação microbiológica do mesmo. É sabido que por não apresentarem conservantes em suas formulações, as soluções salinas comercializadas apresentam segurança microbiológica e garantia terapêutica para o consumidor apenas quando usados de forma única, ou seja, um frasco para cada procedimento. A partir do momento que os frascos são abertos, podem ser facilmente contaminados após 24 horas de exposição ao ar ambiente, mesmo se armazenados na geladeira.

Por ser uma bactéria raramente implicada com infecções oculares, poucos são os relatos para que haja uma definição de padrão de apresentação clínica. Portanto, é de fundamental importância o auxílio fornecido pelo laboratório de microbiologia para a elucidação do diagnóstico, uma vez que o quadro clínico de evolução lenta e indolor difere sobremaneira do encontrado em outras ceratites bacterianas, principalmente ao das bactérias gram-negativas. Diante do observado os principais diagnósticos diferenciais a serem ponderados são as ceratites por Acanthamoeba, fúngica e herpética. As duas primeiras são, possivelmente, mais susceptíveis de confusão com a ceratite em questão, por serem mais relacionadas a traumas e agentes contaminantes, bem como pela distribuição semelhante no ambiente desses agentes em relação à $P$. stutzeri e pelas características evolutivas da lesão.

Dois diferentes estudos visaram determinar as taxas da distribuição hospitalar de P. stutzeri, com a pesquisa bacteriana obtida de amostras de pus, sangue, urina, aspirado traqueal e broncoalveolar de pacientes internados em hospitais universitários durante um período definido. Ambos os estudos concluíram que 1 a $2 \%$ das Pseudomonas spp. isoladas são da espécie P. stutzeri ${ }^{(9,10)}$. Taxas similares $(1.8 \%)$ foram obtidas em um estudo em pacientes com AIDS. A taxa mais elevada relatada mostrou que $3 \%$ de todas as bactérias isoladas de amostras de urina eram P. stutzeri ${ }^{(7)}$. Deste modo, pode-se concluir que a $P$. stutzeri é igualmente distribuído na natureza e em ambientes hospitalares, sendo considerado um microrganismo oportunista, mas raramente patogênico.

Assim como neste relato, testes de sensibilidade para diversos antibióticos referidos em quase todos os outros relatórios epidemiológicos encontrados, demonstraram que a $P$. stutzeri ao contrário da $P$. aeruginosa, sua espécie mais estreitamente relacio- 
nada e um microrganismo reconhecidamente patogênico, era altamente sensível aos antibióticos usados de rotina para bactérias Gram-negativas, sendo a resposta clínica, via de regra, boa ${ }^{(1,3,9)}$.

Esta sensibilidade mais elevada foi explicada por sua ocorrência reduzida em ambientes clínicos e, consequentemente, por sua menor exposição aos antibióticos. Mesmo quando isolados em pacientes imunossuprimidos, nenhuma diferença significativa na susceptibilidade antibiótica foi detectada apesar de tais pacientes serem hospitalizados por longos períodos e geralmente expostos a mais antibióticos e em doses mais elevadas ${ }^{(3)}$.

O interessante é que a despeito da alta suscetibilidade observada nos inúmeros estudos, à exceção das fluoroquinolonas, resistência isolada para quase todas as outras famílias de antibióticos já foi relatada. Brinser citou inclusive resistência a carbenicilina ${ }^{(6)}$. Isto sugere que a $P$. stutzeri possua diferentes mecanismos de resistência. Dois destes já foram descritos: alterações proteicas e de perfis de lipossacarídeos na membrana externa e a presença de $\beta$-lactamases ${ }^{(3)}$.

Em conclusão, este relato ressalta que mesmo sendo um patógeno incomum que geralmente apresenta uma boa resposta a antibióticos, a P. stutzeri pode estar envolvida em quadros infecciosos oculares graves, sendo o estudo microbiológico de suma importância para o diagnóstico etiológico.

\section{Agradecimentos}

Gostaríamos de agradecer a ajuda do Dr. Angelo Ferreira Passos, Chefe do Serviço de Oftalmologia do HUCAM/UFES, por sua valorosa contribuição na revisão deste relato.

\section{ReFERÊNCIAS}

1. Malhotra S, Singh K. Pseudomonas stutzeri associated with conjunctivitis. Indian J Pathol Microbiol. 2008;51(4):572.

2. Lebowitz D, Gürses-Ozden R, Rothman RF, Liebmann JM, Tello C, Ritch R, Valhalla. Late-onset bleb-related panophthalmitis with orbital abscess caused by Pseudomonas stutzeri. Arch Ophthalmol. 2001;119:1723-5.

3. Lalucat J, Bennasar A, Bosch R, García-Valdés E, Palleroni NJ. Biology of Pseudomonas stutzeri. Microbiol Mol Biol Rev. 2006;70(2):510-47.

4. Reisler RB, Blumberg H. Community-acquired Pseudomonas stutzeri vertebral osteomyelitis in a previously healthy patient: case report and review. Clin Infect Dis. 1999;29(3):667-9.

5. Jiraskova N, Rozsival P. Delayed-onset Pseudomonas stutzeri endophthalmitis after uncomplicated cataract surgery. J Cataract Refract Surg. 1998;24:866-7.

6. Brinser JH, Torczynski E. Unusual Pseudomonas corneal ulcers. Am J Ophthalmol. 1977;84:462-6.

7. Stan RJ, Lim EW, Sakazaki R. Unusual cause of urinary tract infection by Pseudomonas stutzeri in Singapore. Jpn J Exp Med. 1977;47(4):311-3.

8. Yee-Guardino S, Danziger-Isakov L, Knouse M, Bingaman W, Sabella C, Goldfarb J. Nosocomially acquired Pseudomonas stutzeri brain abscess in a child: case report and review. Infect Control Hosp Epidemiol. 2006;27:630-2.

9. Ergin Ç, Mutlu G. Clinical distribution and antibiotic resistance of Pseudomonas species. East J Med 1999;4:65-9.

10. Noble RC, Overman SB. Pseudomonas stutzeri infection. A review of hospital isolates and a review of the literature. Diagn Microbiol Infect Dis. 1994;19(1):51-6.

\author{
Endereço para correspondência: \\ Hospital Cassiano Antônio Moraes (HUCAM) - \\ Departamento de Oftalmologia \\ R. Marechal Campos s/no - Maruípe \\ CEP 05409-011 - Vitória (ES), Brasil \\ Telefone: (27) 3335-7303 \\ E-mail: fellipeberno@yahoo.com.br
}

